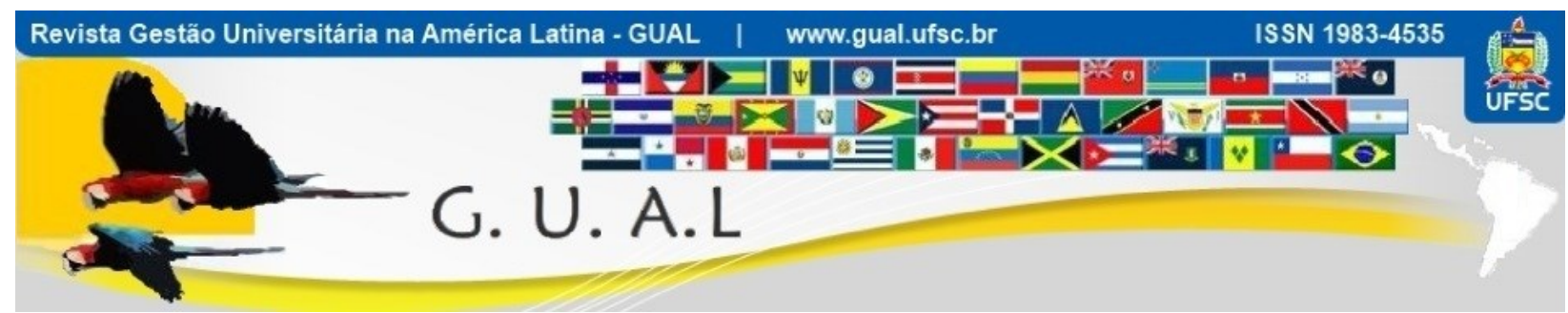

DOI: http://dx.doi.org/10.5007/1983-4535.2017v10n4p1

\title{
PERFIL DO GESTOR E DESEMPENHO ECONÔMICO- FINANCEIRO DAS INSTITUIÇÕES DE ENSINO SUPERIOR: O CASO DAS COMUNITÁRIAS BRASILEIRAS PARTICIPANTES DO COMUNG
}

\author{
PROFILE OF THE MANAGER AND ECONOMIC AND FINANCIAL \\ PERFORMANCE OF HIGHER EDUCATION INSTITUTIONS: THE CASE OF THE \\ BRAZILIAN COMMUNITY PARTICIPANTS OF COMUNG
}

Jênifer de Brum Palmeiras, Mestranda Universidade de Passo Fundo - UPF jeniferb@upf.br

Denize Grzybovski, Doutora Universidade de Passo Fundo - UPF gdenize@upf.br

Recebido em 25/novembro/2016

Aprovado em 16/outubro/2017

Sistema de Avaliação: Double Blind Review

Esta obra está sob uma Licença Creative Commons Atribuição-Uso. 


\title{
RESUMO
}

O objetivo deste artigo é analisar a relação do perfil do gestor com a performance das IESs comunitárias brasileiras participantes do COMUNG. O pressuposto teórico é de que a formação profissional do gestor das universidades comunitárias apresenta relação positiva com os resultados organizacionais e com o modelo de gestão adotado. A natureza das IESs comunitárias brasileiras é de organização da sociedade civil, as quais deveriam ser geridas pelo modelo de administrativa participativa e pautada na autogestão, distanciando-se do modelo clássico, que mostra-se limitado no contexto de mudanças ambientais e com grandes competidores. Houve mudanças significativas no ambiente institucional, que impõem reflexões críticas sobre práticas consolidadas, sem prejuízos à liberdade acadêmica. Trata-se de uma pesquisa exploratória e descritiva desenvolvida com 15 instituições de ensino superior membros do Consórcio das Universidades Comunitárias Gaúchas(Comung) brasileira. Os resultados evidenciam que existe correlação do perfil de um dos gestores (Reitor) com os resultados de perfomance, de reconhecimento externo (prêmios) em relação à sustentabilidade institucional.

Palavras chave: Gestão universitária. Desempenho econômico-financeiro. Instituições de ensino superior comunitárias.

\begin{abstract}
The objective of this article is to analyze the relation of the profile of the manager with the performance of the Brazilian community HEIs participating in COMUNG. The theoretical assumption is that the professional training of the manager of the community universities presents a positive relation with the organizational results and with the management model adopted. The nature of Brazilian community HEIs is a civil society organization, which should be managed by the participative administrative model and based on self-management, distancing itself from the classical model, which is limited in the context of environmental changes and with major competitors. There have been significant changes in the institutional environment, which impose critical reflections on consolidated practices, without prejudice to academic freedom. This is an exploratory and descriptive research developed with 15 higher education institutions members of the Consortium of Brazilian Community Universities (Comung). The results show that there is a correlation between the profile of one of the managers (Dean) and the performance of external recognition (awards) in relation to institutional sustainability.
\end{abstract}

Keywords: University Management. Economic and Financial Performance. Community Higher Education Institutions. 


\section{INTRODUÇÃO}

Estudos sobre performance organizacional, gestão universitária e perfil dos gestores são raros na literatura gerencial, dentre os quais destaca-se Meyer (2000), que refletiu teoricamente a respeito do "novo conceito" de gestão universitária contemplando as habilidades do administrador universitário. Os principais trabalhos sobre gestão universitária nas últimas duas décadas tem sido elaboradas por Meyer (1998), Tashizawa e Andrade (2001) e Meyer; Mangolim (2006). No entanto, a necessidade de sobrevivência organizacional desafia a proposição de contemplar as pessoas humanas no processo de gestão dos recursos de uma instituição de ensino superior (IES) e o compromisso social e ambiental na avaliação da performance organizacional, tudo isso sem que percam-se a cultura acadêmica e a proposta de universalidade do conhecimento.

Nesse sentido, Hardy e Fachin (1996) abordam que o processo decisório de qualquer organização enfrenta desafios, os quais foram maximizados no contexto econômico e social complexo da atual realidade brasileira, sendo estes maximizados nas IESs comunitárias, as quais enfrentam a concorrência com IESs privadas e de capital especulativo. Nas IESs comunitárias, há dificuldade dos gestores universitários compreenderem a complexidade presente nos processos decisórios de forma sistêmica, além do entrave da falta de profissionalismo na gestão, visto que as IESs em geral não possuem orientação empresarial. Zabalza (2007) afirma que o corpo docente acaba por administrar a instituição, realizando atividades burocráticas de competência de profissionais formados em Administração.

Apresenta-se tal problemática tendo em vista que as IESs comunintárias são uma categoria distinta das organizações sociais, que se aproxima bastante daquelas organizações de prestação de serviços, ressalta-se a diferença entre as demais instituições, a empresa, por exemplo, reserva para análise e propostas de mudanças a aplicação de normas condicionadas a parâmetros adequados à sua natureza e às funções, que são específicas de uma instituição de ensino (TACHIZAWA, 2001, p. 49).

O objetivo deste artigo é analisar a relação do perfil do gestor com a performance das IESs comunitárias brasileiras participantes do COMUNG. O pressuposto teórico é de que a formação profissional do gestor das universidades comunitárias apresenta relação positiva com os resultados organizacionais e com o modelo de gestão adotado. O contexto vivenciado pelas IESs comunitárias pressupõe-se a necessidade de mudança de postura do gestor, voltada para uma gestão universitária contemporânea, distanciando-se dos tradicionais modelos 
burocráticos e orientando suas ações com base na gestão estratégica de pessoas. Uma vez estruturada em torno dos objetivos organizacionais que buscam maximizar o desempenho das pessoas e basear-se em suas competências, sem prejuízo da cultura acadêmica, as IES podem ser tão competitivas quanto são as empresas do setor privado. Por isso questiona-se o perfil do gestor das universidades comunitárias.

A atuação do gestor universitário estruturada nos princípios clássicos da administração, no modelo burocrático de gestão e no desempenho dos recursos humanos (acadêmicos e técnicos administrativos) e sem prejuízo da liberdade acadêmica é um dos grandes desafios à sustentabilidade das instituições do ensino superior (IESs) (DESIDERIO, 2004). Contudo, aponta Ribeiro (2014), o que mais se distancia dos compromissos da gestão universitária é a competitividade e sustentabilidade institucional, a garantia de meios materiais e condições de autonomia.

Conforme relatório de pesquisa realizada pelo Conselho Federal de Administração (CFA) e os relatórios do Exame Nacional de Cursos, sobre a Avaliação das condições de oferta de cursos de graduação, as instituições de ensino superior estão entrando em uma nova fase de desenvolvimento, impelidas pelas mudanças do mercado (CFA, 2011; BRASIL, 1999). Tashizawa e Andrade (2001) afirmam que as IESs não mais atendem à necessidade de formação de profissionais autônomos e preparados para lidar com ambientes de mudança e incerteza e, em sua maioria, não estão preparadas para enfrentar os desafios da concorrência a que estão expostas. Portanto existe a necessidade de mais reflexão sobre a gestão universitária no contexto da Ciência da Administração, e a maioria das referências encontradas, está sendo discutido na área da Educação, revelando ser um tema no qual os pesquisadores da Administração tem dado pouca atenção. A gestão estratégica de uma organização universitária precisa refletir sobre qual seu espaço e como ele é ocupado dentro da Teoria da Administração (HARDY; FACHIN, 2000; COHEN; MARCH; OLSEN, 1972).

Para Cardim (2000), tornam-se relevantes as competências, a formação profissional e a experiência dos gestores universitários para a tomada de decisões, as quais, por sua vez, dependem de oportunidades para aprender e experimentar novas capacitações e habilidades. Um estudo de Cynthia Hardy e de outros profissionais, reproduzindo no livro Gestão Estratégica na Universidade Brasileira, diz que há tipos de tomada de decisões nas universidades. Há um nível de decisão por determinação administrativa, isto é, tomada por administradores de topo. Normalmente, na universidade, este tipo de decisão envolve aquelas 
que se repercutem diretamente no staff de apoio da administração de topo, ou da Reitoria. Há decisões de natureza financeira ou física, e um tipo de decisão mais comum, que é o da decisão por julgamento profissional. Os professores decidem como ensinar ou conduzir as suas aulas ou como fazer as suas pesquisas. São decisões influenciadas por normas profíssionais, não são decisões determinadas pela universidade ou por regras formalizadas pela universidade, muitas vezes são tomadas pela categoria, pela disciplina a que cada professor está ligado. Ele está muito mais voltado ao que a comunidade internacional de físicos, de administradores, de biólogos, de engenheiros estuda, trabalha e concebe do que a alguma decisão específica tomada no âmbito estrito da universidade (HARDY; FACHIN, 2000)e há as decisões por escolha coletiva, que são aqueles processos que ocorrem nos órgãos decisórios, nos diferentes tipos de comissões que existem em qualquer universidade.

Os restultados do presente estudo são apresentados a seguir, em quatro partes além desta introducao. Na parte 2 são apresentados os fundamentos teóricos da gestão universitária e da educacao superior brasileira, com a pretensão de alocar no espaço da pesquisa a compreensão da teoria da administração. Na parte 3 constam os procedimentos metodológicos que orientaram a investigação empírica, realizada com dados secundários em documentos institucionais públicos. Na parte 4 são apresentados os resultados da pesquisa, aos quais se seguem as conclusõe do estudo.

\section{FUNDAMENTAÇÃO TEÓRICA}

\subsection{EDUCAÇÃO SUPERIOR BRASILEIRA}

No Brasil a universidade, como instituição, foi criada a partir da década de 1920, mas sua expansão deu-se, de forma mais acelerada a partir da década de 1950. Na concepção de Rossato (2005, p.132), foi após 1965 que realmente se ampliou o número de faculdades, institutos, escolas isoladas, federações e universidades buscando atender aos interesses da modernização. Intensificando-se na metade da década de 1980 em diante, uma nova perspectiva de instituição de ensino superior surgiu no âmbito do ensino privado: as instituições comunitárias, muitas das quais se constituiriam, posteriormente, em universidades comunitárias. Segundo Longhi (1998), em especial no Rio Grande do Sul, em face das necessidades de desenvolvimento econômico e sociocultural e em decorrência de ausência do poder público, muitas comunidades cujas iniciativas privadas "já tinham tradição nos níveis anteriores do ensino organizaram-se para que tivesse prosseguimento através de cursos 
superiores e faculdades"(p.249), as quais lentamente foram obtendo o reconhecimento como universidades e constituindo o segmento das comunitárias.

Bittar (2006) orienta que as universidades comunitárias formam um sistema distinto de educação superior. A denominação "comunitária" emergiu no momento em que a sociedade brasileira se organizava através de representações para acompanhar e pressionar o Congresso Nacional, que elaborava uma nova Constituição para o país, contudo, a propsota original reside na década de 1970. Longhi (1998) afirma que os movimentos associativos dessas IES no Rio Grande do Sul iniciou ainda na década de 1970, com a implantação do DGE38. Tais movimentos foram ganhando espaço e força em nível regional e nacional, tanto entre instituições confessionais como entre as laicas, propiciando a constituição e a implantação do Consórcio das Universidades Comunitárias Gaúchas (Comung).

O Comung é uma rede de universidades comunitárias do Brasil sediada no estado do Rio Grande do Sul. Conforme divulgação da identidade, são 15 instituições de ensinosuperior integradas e que têm o objetivo de planejar e promover ações conjuntas, otimizando as relações internas com instituições públicas e com a sociedade; assegurar a maior força na defesa dos interesses educacionais dos seus participantes, através de negociações mais significativas no âmbito público em todas as esferas administrativas da sociedade civil organizada; alcançar maior representatividade perante os organismos financiadores internacionais pela capacidade de integração político-institucional; proporcionar e operacionalizar convênios, acordos protocolos com instituições e órgãos governamentais e privados, tanto nacionais como internacionais; acentuar o trabalho com organismos públicos, em todos os níveis, e/ou privado, em especial a área da ciência e tecnologia, assegurando a presença ativa do consórcio na implantação de pólos tecnológicos, e viabilizar a realização de eventos que respondam ao interesse do ensino superior e da pesquisa.(COMUNG, 2016).

As principais características do Comung são a transparência administrativa, a austeridade da gestão financeira, o controle público das atividades, a ênfase no desenvolvimento da comunidade local e regional, além do desenvolvimento de atividades sem fins lucrativos (COMUNG, 2016). O que caracteriza esse movimento é a unanimidade de suas metas. No bojo dessa articulação se desenvolvem iniciativas como: o Programa de Avaliação Institucional das Universidades Comunitárias Gaúchas (Paiung), com o duplo objetivo de aperfeiçoamento de projetos políticos e sociopolíticos dessas instituições, subsidiando o 
Ministério da Educação no estabelecimento de critérios para a avaliação das universidades do país; a qualificação docente, que ocorre em cursos de mestrados e doutorados próprios ou consorciados com IES reconhecidas pela Capes no país; a integração das universidades com a educação básica, buscando apoiar a qualificação e a capacitação de professores do ensino fundamental e médio; a realização de seminários temáticos, reunindo pesquisadores por áreas do conhecimento e estimulando a formação de redes interinstitucionais de pesquisa; o desenvolvimento integrado das regiões de abrangência das universidades comunitárias.

Diante do exposto pode-se considerar que o modelo comunitário de universidade surgiu como uma iniciativa alternativa de instituição de ensino superior que, para Frantz (2002), não foi uma iniciativa de privatizar o espaço da educação. Afirma o referido autor que as IES comunitárias gaúchas representam a concretizacao de um esforço coletivo pela construção de novos espaços públicos da educação superior no contexto brasileiro, já que estas instituições de ensino superior não poderiam ser caracterizadas como públicas, pois não eram federais, nem privadas comerciais ou empresariais. Por isso é que até então eram caracterizadas como instituições de ensino superior "públicas não estatais".

Neves (2002) destingue as IES privadas das comunitárias pelas primeiras serem mantidas por pessoas físicas ou jurídicas de direito privado, enquanto que as segundas são mantidas por pessoas físicas ou jurídicas da comunidade. Estas mantenedoras são cooperativas/associações de professores e alunos, congregacoes religiosas e outros coletivos e que incorporam representações dos diferentes stakeholders, inclusive representantes da comundidade, nas diferentes instâncias decisórias.

\subsection{GESTÃO UNIVERSITÁRIA}

Partindo do pressuposto de que auto-administrar ou autogerir uma instituição significa dar autonomia ou permitir que os membros desta instituição decidam seus rumos e o uso de seus recursos, cabe refletir as relações entre a Reitoria, a administração central, as unidades e forma de gerenciar a Universidade. São estas diferenças que remete a refletir sobre o que significa a gestão das universidades.

O gerenciamento dos recursos compreende tanto aspectos acadêmicos, quanto financeiros e patrimoniais, onde no artigo 207 da Constituição Federal, expressa que as universidades brasileiras gozam de autonomia didático-científica, administrativa e de gestão financeira e patrimonial, com indissolubilidade entre ensino, pesquisa e extensão. As 
universidades brasileiras utilizam o modelo de gestão da democracia representativa: um grupo de representantes docentes, nas diferentes linhas decisórias, administra em nome dos demais.

Em sua experiência na Reitoria da UNICAMP, Carpitério (2007, p. 109) afirma que a gestão das universidades é dividida em o que fazer, quais objetivos?, como fazer, e comunicar institucionalmente., e assim ponderada a administração entre os representantes, docentes, discentes e funcionários, seus direitos, responsabilidades devem refletir em seu entendimento individual pelo seu conhecimento, experiência, daí, as diferenças em termos de participação na escolha de seus dirigentes através dos colegiados, conselhos, diretórios, sindicatos.

Administrar a Universidade, o fazer, deve-se submeter aos objetivos da instituição, deve ser, estrategicamente, potencializar a capacidade da instituição para prestar melhores serviços, aumentar o ensino de qualidade, pesquisa e extensão. Os representantes devem não só ter o comprometimento de seus segmentos básicos, mas também atuar junto aos profissionais externos à docência, liberdade à política de pessoal, garantia de recursos, estímulo à eficiência (CHAUI, 1980, p. 34).

A prática administrativa terá a resposta de acordo com seus objetivos quando equilibrada entre a qualidade acadêmica, relevância social e o acesso ao conhecimento (MEYER JUNIOR, 1998; BALDRIDGE, 1971). O conhecimento de seus membros e da sociedade sobre o funcionamento da instituição, e no fato de concordar ou não com a forma que está sendo gerida, será feito através da informação, da prestação de contas, das consultas, das explicações honestas sobre as ações administrativas.

O papel da universidade como produtora de conhecimento, muitas vezes, faz com que seu entendimento sobre gestão diverge sobre o próprio conceito de administração, em alguns momentos a figura de uma reitoria que administra, é autônoma perante a comunidade, é confundida com o "patrão", o chefe, e não um membro eleito para representar os demais, daí levanta-se a questão da experiência, da capacidade de entendimento dos aspectos acadêmicos, administrativos e sociais (ROSSETTO, 2005)

É inegável reconhecer que, o avanço da universidade em termos, de ensino, pesquisa e extensão, necessita de contínuos aperfeiçoamentos em formação técnico-administrativos de seus gestores para o adequado funcionamento do sistema universitário brasileiro, seja ele, público, comunitário ou privado.No pensamento de Mühl, os diagnósticos apontam para a necessidade de se acabar com as experiências de "administração amadora", baseada, especialmente, na gestão colegiada, e implantar uma forma de administração centralizadora, 
vertical, orientada por critérios de desempenho econômico. A via democrática de escolha dos dirigentes acaba conduzindo, em geral, aos cargos administrativos pessoas incompetentes [...], para tanto, recomenda-se os especialistas, que deve haver a substituição dos espaços de gestão baseados nos colegiados de professores por setores compostos de técnicos e serviçais sistêmicos, implicando numa reforma na estrutura universitária (2009, p.96).

Um dos questionamentos que têm sido feitos pelos críticos e pelos especialistas reformadores atinge diretamente a validade e eficácia administrativa da gestão democrática. É um empecilho para a solução de problemas financeiros e administrativos que as instituições vêm sofrendo. A falta de inovação, a ineficácia em atender as novas demandas, a perda de tempo em discussões políticas, a manutenção de uma estrutura burocrática defasada, que tem impedido uma agilidade maior das IES em se modernizar, são decorrências da organização democrática que impera nas universidades (MÜHL, 2009, p.100).

A instituição de ensino é fruto da união de educadores, com filosofia, princípios, diretrizes e estratégias comuns, transformadores da sociedade. Deve ser visualizada com um conjunto de partes em constante interação, orientando-se para determinados fins, em permanente interdependência com o ambiente externo. A adoção do enfoque sistêmico, que considera a instituição um macrossitema aberto, interagindo com o meio ambiente, pode ser entendida como um processo que busca converter recursos em produtos, ou seja, serviços educacionais, em consonância com seu modelo de gestão, missão, crenças e valores corporativos.

É no seio da Teoria Neoclássica que se (re)fundamentam as funções de um administrador: planejamento, organização, direção e controle, as quais compõem o processo administrativo. Muito semelhante à definição de Fayol para estas funções: prever, organizar, mandar, coordenador e controlar. Como ponto fundamental desta teoria, aparece a necessidade de contemplação do fator social intimamente atrelado ao processo administrativo.

Isso leva o administrador conhecer, além dos aspectos técnicos e específicos de seu trabalho, os aspectos relacionados à direção de pessoas dentro das organizações. Visto também como educador, o gestor agrega valor a sua função, pois estará contribuindo para a formação educativa do sujeito-trabalhador (Rodrigues, 2004, p. 54). De um bom gestor espera-se, nesta perspectiva, capacidade de influenciar as pessoas que lidera com o objetivo de mobilizá-las à obtenção de um objetivo comum, extrapolando aí, o ambiente empresarial. 
O início de uma época marcada pela competitividade traz para o centro do poder organizacional o foco nos resultados, a primazia pela qualidade, a preocupação com o cliente e com sua fidelidade, a importância de recursos humanos capacitados, ou seja, para a gestão das competências da empresa e dos funcionários, desta vez necessitada de novas habilidades para a gestão das pessoas, que, envolvidas neste processo, precisam rapidamente, de um perfil mais adequado as novas demandas do mercado.

A área educacional universitária tem buscado maior profissionalização de seus cargos gerenciais a partir da necessidade do gestor na área educacional de conciliar a gestão administrativa, pedagógica, acadêmica e científica. Para o desempenho da função com eficácia, faz-se necessário a identificação das atividades realizadas, bem como dos papéis gerenciais assumidos na sua atuação profissional, entendo papel como a "forma de funcionamento que o indivíduo assume no momento específico em que reage a uma situação específica, nas quais outras pessoas estão envolvidas" (Silva, 2005, p. 118). Esta identificação é vista como ponto inicial para investigar as competências gerenciais necessária para o exercício da função do profisssional na Educação Superior.

Considerando a responsabilidade fundamental da universidade, que é a de tornar o conhecimento (que lhe cabe conversar, organizar e produzir) acessível ao corpo social, por meio, principalmente, do ensino superior, pode-se dizer que um curso de nível superior, define-se por ser um processo de transformação do conhecimento em condutas profissionais e pessoais, complexas, abrangentes e significativas para a sociedade. Para que um processo que apresente tais exigências se concretize de maneira satisfatória e necessária, é preciso que haja, na instituição, alguém ou órgão que tenha como papel administrá-lo, dirigi-lo, coordená-lo. E essa responsabilidade, do ponto de vista regimental, é do gestor universitário (MEYER, 2006, $\mathrm{p}$ 68).

A gestão de uma Universidade é uma função de bastante relevância para a efetivação de um ensino de qualidade, isso porque essa função também é administrativa, com a busca de eficiência dos meios de trabalho, e também função com dimensões pedagógicas, acadêmicas e científicas, no campo profissional dos cursos oferecidos pela IES (ZABALZA, 2007).

Nas Universidades, os gestores devem obrigatoriamente desenvolver habilidades em política, porém não politicagem, que é considerada o lado ruim da política, quando qualquer membro da organização converte seu poder em ação, estão se dedicando à política. Os que possuem boas habilidades políticas têm capacidade para usufruir eficazmente das bases de seu 
poder (COSTA 2009, p. 24). O autor segue afirmando que para exercer um cargo gerencial numa IES, eles são considerados agentes de mudança, que fornecem estímulo e assumem a responsabilidade no processo de mudança, assim "as organizações, seja ela qual for, necessitam de líderes transformacionais que as reformulem e consigam que os funcionários vistam a camisa dos motins que acompanham as mudanças abruptas" .O professor que participa da administração universitária, precisa administrar, coordenar e dirigir, estabelecendo parcerias e criando um ambiente de cooperação e troca (CHAUI, 1980, p. 33).

Um professor que informe e se envolva, disposto a expor suas intenções e concepções sobre ensino e aprendizagem. Busque diálogo e estabeleça relações de confiança com a comunidade interna e externa da universidade. Esse professor deve administrar sua própria formação contínua e, para isso esteja disposto a fazer uma reflexão profunda de sua práticas pedagógicas, que tome consciência de si, do que faz e de suas competências profissionais, procurando estabelecer relações entre o saber com a ação (Costa, 2009, p. 24).

As informações se multiplicam a cada dia e os conhecimentos precisam ser aprimorados no mesmo ritmo. A empresa que ensina, ao articular essas duas dimensões, tempo e conhecimento, estabelece um sistema interativo de aprendizagem por toda a comunidade e rede de relacionamentos, ou seja, a organização pode vir a ser um espaço por excelência para onde devem convergir todas as informações interessantes ao desenvolvimento do seu negócio, seja ele, com fins lucrativos ou ensino (Christóvam, 2009, p. 46).

E o gestor desta organização, possui um conjunto de conceitos e valores a serem ensinados ou partilhados, eles dão sustentação às ideias, mas estas não são tudo, a forma como os demais membros da organização aprendem, percebem ou recebem essas ideais não são lineares, aprendizes precisam estar motivados e inspirados para gerar comprometimento, que por sua vez gera alinhamento estratégico, e cabe ao gestor desenvolver habilidades fazer isso acontecer (Christóvam, 2009, p. 47).

Zabalza expoe a complexidade para definir a função gerencial dentro de uma IES, que apesar de tantos avanços, permanece ainda em patamares falaciosos, com práticas centralizadoras que inibem o crescimento das pessoas ao redor, acarreta a uma mudança na prática de gestão, mudando a atuação do líder, e mais complexo será avaliar essa atuação do gestor, que hoje é nomeado e dispensado como "técnico de futebol" (2007, 99). Para ser gestor numa IES é preciso fazer uma gestão output. Gestão não é esforço, o gestor pode trabalhar 12 horas por dia, ser o primeiro a chegar, e anotar todos os outros professores que 
chegaram atrasados, cobrar as salas de aula limpas, do professor que não veio e não avisou, e terminar o dia convencido de que fez o melhor para a universidade, mas na verdade foi tempo jogado fora, não produziu resultados, e pior, concentrou na figura do gestor, atribuições e responsabilidades que não são só suas (Pestana, 2009, p. 53).

Ao definir o papel do gestor, sua área de atuação, e isso estar descrito no organograma da instituição, combinando com os funções dos respectivos funcionários, certamente poderá haver uma boa administração, porém muito dos gestores se questionam em relação às práticas ditas como empresarias dentro de uma universidade, e aí é o maior problema, não enxergam a instituição como uma empresa que não possui fins lucrativos, e sim prestam serviços educacionais, via de regra, essa é a única diferença das demais empresas de prestação de serviços no mercado.

\section{METODOLOGIA}

$\mathrm{Na}$ busca das questões particulares das questões relativas à performance organizacional, foi realizada uma pesquisa exploratória e descritiva desenvolvida com 15 instituições de ensino superior membros do Consórcio das Universidades Comunitárias Gaúchas(Comung) brasileira. A representatividade da amostra se dá pelo fato de o Consórcio atende mais de $50 \%$ dos universitários gaúchos, oferecendo 1.489 cursos de graduação e pósgraduação, são 202.020 mil alunos, atendidos por 9.190 professores e mais de 11 mil funcionários (COMUNG, 2016).

O conjunto das IESs selecionadas para o estudo estão apresentadas na Figura 1, dispostas no mapa do Brasil e com destaque para a sua localizaçao no Estado do Rio Grande do Sul.

Figura 1 Mapa de localização das IESs membros do Comung.

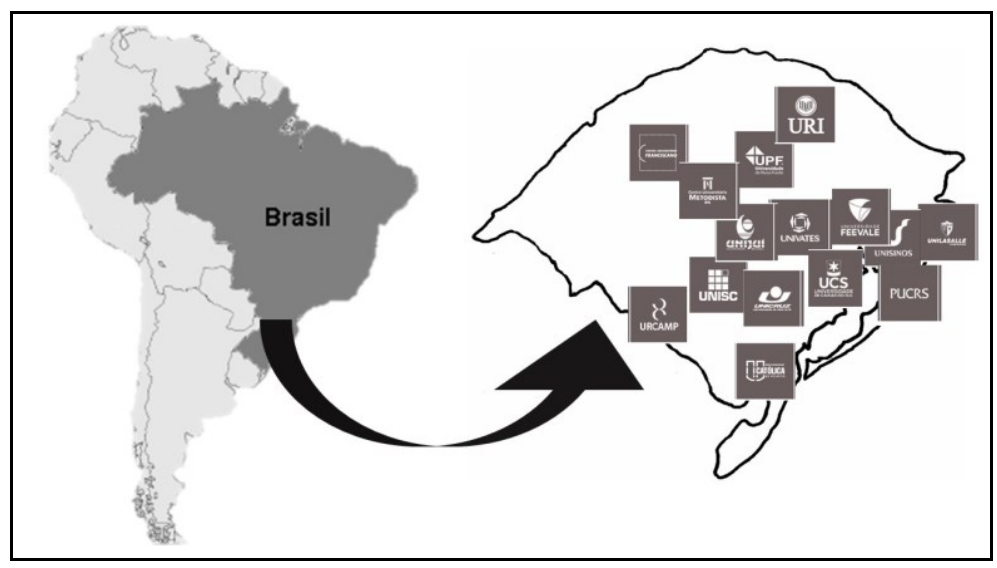

Fonte: Comung (2016). 
Os dados foram coletados nos documentos e nas páginas eletrônicas institucionais (homepage) de cada IESs e posteriormente foram organizados em duas categorias analíticas (perfil do gestor; performance organizacional). Com relação aos procedimentos sistemáticos para validar as informações apresentadas nos Relatórios da Administração, foi utilizada Análise de Conteúdo considerando as categorias apresentadas na Figura 2.

Figura 2 Esquema analítico

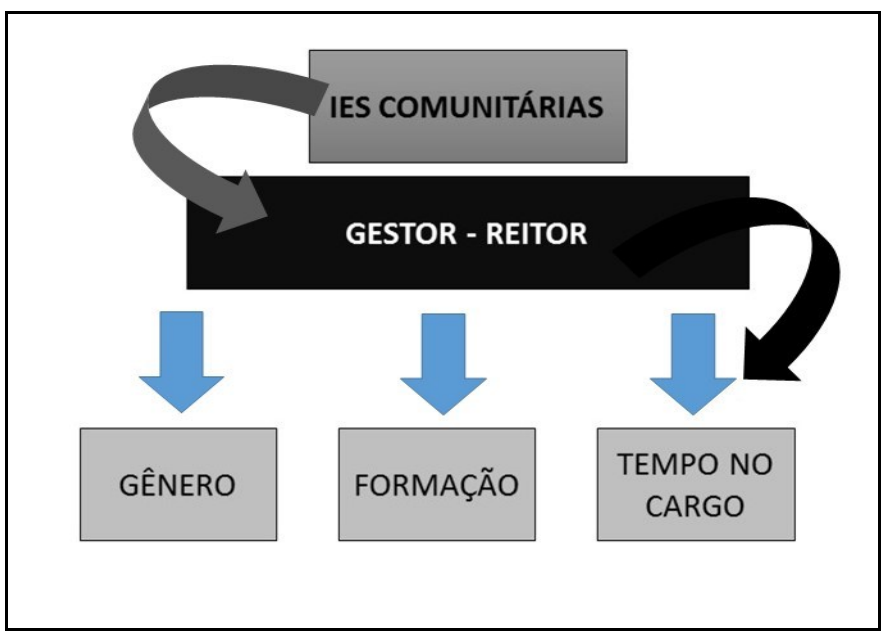

Fonte: As autoras.

\section{APRESENTAÇÃO E DISCUSSÃO DE RESULTADOS}

\subsection{ESTRUTURA E INSTÂNCIAS DECISÓRIAS NAS IES COMUNITÁRIAS}

Em 1993, um grupo de instituições comunitárias localizadas no estado do Rio Grande do Sul, no Brasil, firmou um Protocolo de Ação Conjunta para constituir o Consórcio das Universidades Comunitárias Gaúchas - Comung. O objetivo era viabilizar um processo integrativo que resultasse no fortalecimento individual das instituições e no consequente favorecimento da comunidade universitária rio-grandense e da sociedade gaúcha.

Constituído oficialmente em 1996, o Comung hoje representa uma série de conquistas para as instituições: programas e experiências compartilhadas, avaliação institucional, intercâmbios de professores e de alunos, qualificação e treinamento de funcionários e professores, fórum de tecnologia da informação, integração entre diversos segmentos como assessorias jurídicas, recursos humanos, assessorias de comunicação e bibliotecários. Além disso, busca de forma conjunta, por meio de convênios e políticas públicas, incentivos à formação acadêmica da população, à promoção de atividades culturais, bem como ao desenvolvimento de ações de inovação e empreendedorismo, entre outras. 
Integrado por 15 Instituições de Ensino, o Comung é o maior sistema de educação superior em atuação no Rio Grande do Sul. As Instituições que formam o Comung representam uma rede de educação, ciência e tecnologia que abrange quase todos os municípios do Estado. No Quadro 1 constam as pricipais características do espaço onde as IES estão localizadas.

Quadro 1 IESs comunitárias e características do espaço em que estão localizadas.

\begin{tabular}{|l|l|c|c|c|}
\hline \multicolumn{1}{|c|}{ IES } & \multicolumn{1}{c|}{ Cidade } & Habitantes & $\begin{array}{c}\mathbf{N}^{\mathbf{0}} \text { de } \\
\text { Estudantes }\end{array}$ & $\begin{array}{c}\text { Economia } \\
\text { prevalente }\end{array}$ \\
\hline UNIFRA & Santa Maria & 276.108 & 7.454 & Comércio \\
\hline FEEVALE & $\begin{array}{l}\text { Novo } \\
\text { Hamburgo }\end{array}$ & 239.051 & 16.500 & Indústria \\
\hline $\begin{array}{l}\text { CENTRO UNIVERSITÁRIO } \\
\text { METODISTA }\end{array}$ & Porto Alegre & 1.481 .019 & 5.000 & Comércio \\
\hline PUCRS & Porto Alegre & 1.481 .019 & 28.876 & Comércio \\
\hline UCS & Caxias do Sul & 474.853 & 34.291 & Indústria \\
\hline UNICRUZ & Cruz Alta & 62.776 & 3.200 & Agricultura \\
\hline UNIJUÍ & Ujuí & 82.833 & 10.000 & Agricultura \\
\hline UNILASALLE & Canoas & 323.827 & 10.684 & Indústria \\
\hline UNISC & $\begin{array}{l}\text { Santa Cruz do } \\
\text { Sul }\end{array}$ & 130.354 & 13.292 & Indústria \\
\hline UNISINOS & São Leopoldo & 214.210 & 31.000 & Indústria \\
\hline UNIVATES & Lajeado & 71.481 & 12676 & Indústria \\
\hline UCPEL & Pelotas & 342.873 & 5.000 & Agronegócio \\
\hline UPF & Passo Fundo & 196739 & 21.879 & Agropecuária \\
\hline URCAMP & Bagé & 116.794 & 5.682 & Agropecuária \\
\hline URI & Erechim & 101.752 & 12.200 & Indústria \\
\hline
\end{tabular}

Fonte: Dados da pesquisa (2016).

Os dados apresentados no Quadro 1, descrevem a cidade sede, onde o centro administrativo da IES se localiza. Entre as IES estudadas 12, possuem mais de um campi localizados em cidades próximas, que não foram objetos para esta pesquisa.

A gestão das IESs comunitárias é realizada de forma colegiada e todas elas tem a mesma estrutura organizacional, cujo gestor principal, denominado Reitor, é assessorado por “vice-reitores" ou "pró-reitores". Observe os dados desta estrutura colegiada na Figura 3, que reproduz o que é comum entre todas as IES membros do Comug, as quais são submetidas à decisões colegiadas das mantenedoras (fundações, associaçoes ou congregações). 
Figura 3 Estrutura organizacional comum nas IESs membros do Comung

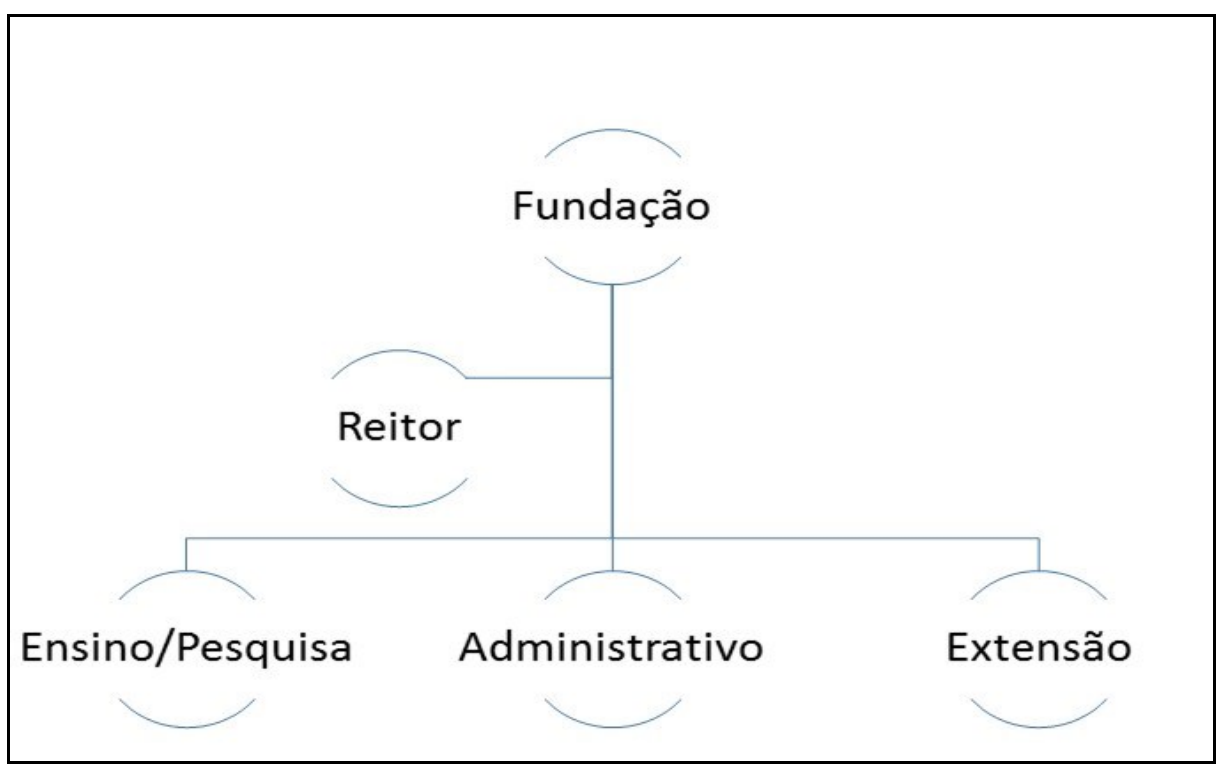

Fonte: As autoras.

As decisões colegiadas são tomadas por docentes que ocupam, por eleição ou escolha colegiada entre os pares, cargos de gestão das IES. Em geral, os gestores são designados pelos colegas por meio de eleições departamentais para representá-los em diferentes instâncias de decisão (departamentos, comissões, comitês e conselho), que tem o Conselho Universitário o órgão máximo. O Conselho Universitário tem função deliberativa e de planejamento da Universidade nos planos acadêmico, administrativo, financeiro, patrimonial e disciplinar, tendo sua composição, competências e funcionamento definidos no Estatuto e no Regimento Geral das Univeridades. Em nenhuma delas os referidos cargos são ocupados por profissionais da gestão contratados para este fim.

\subsection{PERFIL DO GESTOR DAS IESs COMUNITÁRIAS}

Os gestores das IESs comunitárias membros do Comung são reitores jovens com a média de idade de 45 anos, com formaçao em diferentes áreas do conhecimento, com prevalência nas Ciências Sociais Aplicadas (Direito, 4; Economia, 1; Contábeis, 1) e nas Ciências Humanas (Filosofia, 4). A área da educação, principal serviço prestado pelas IESs, está representada por dois reitores (Unifra, Feevale) e com formação no curso de Administração não há nenhum reitor. 
Tabela 1 Perfil dos reitores das IESs do Comung.

\begin{tabular}{l|l|l|l|c}
\hline \multirow{2}{*}{ IES } & \multicolumn{4}{c}{ PERFIL DO GESTOR } \\
\cline { 2 - 5 } & \multicolumn{1}{|c|}{ Gênero } & $\begin{array}{c}\text { Curso de } \\
\text { Formação }\end{array}$ & Cargo & $\begin{array}{c}\text { Tempo de } \\
\text { atuação no } \\
\text { cargo, em anos }\end{array}$ \\
\hline UNIFRA & Feminino & Educação* & Reitora & 2 \\
\hline FEEVALE & Feminino & Educação & Reitora & 2 \\
\hline CENTRO UNIVERSITÁRIO & Feminino & Direito & Reitora & 2 \\
\hline METODISTA & Masculino & Filosofia & Reitor & 12 \\
\hline UCS & Masculino & Filosofia & Reitor & 2 \\
\hline UNICRUZ & Feminino & Saúde & Reitora & 3 \\
\hline UNIJUÍ & Masculino & Contábeis & Reitor & 2 \\
\hline UNILASALLE & Masculino & Filosofia & Reitor & 2 \\
\hline UNISC & Feminino & Direito & Reitora & 2 \\
\hline UNISINOS & Masculino & Filosofia & Reitor & 2 \\
\hline UNIVATES & Masculino & Economia & Reitor & 17 \\
\hline UCPEL & Masculino & Saúde* & Reitor & 4 \\
\hline UPF & Masculino & Direito* & Reitor & 6 \\
\hline URCAMP & Feminino & Engenharia & Reitora & 6 \\
\hline URI & Masculino & Direito* & Reitor & 2 \\
\hline
\end{tabular}

(*) não tem título de doutor

Fonte: Dados da pesquisa

De acordo com os dados apresentados na Tabela 1, observa-se que a maioria dos reitores são homens (9) e também são os que atuam há mais tempo no cargo. O reitor da PUC/RS, uma IES que por decreto é uma congregação para a educação católica, está no cargo há 12 anos; o reitor da Univates, uma IES que tem uma trajetória que se confunde com a história recente do Vale do Taquari, e nasceu para suprir a demanda da comunidade que não era atendida pelas IES da regiao, Unisinos e UCS, está no cargo há 17 anos. Exercendo o cargo há 6 anos estão o reitor da UPF e da URCAMP.

\subsection{DISCUSSÃO DOS DADOS}

No desenvolvimento desta pesquisa, os dados que foram analisados, fazem parte de uma engrenagem que deverão ser discutidos a partir do contexto em que estão inseridos, o cenário político-econômico, e o processo de implantação do Comung no Brasil, o discurso e o poder do capitalismo neoliberal sobre a educação, e especificamente, sobre essas entidades, ou em toda a lógica e a trajetória das IESs comunitárias.

No contexto em análise, a universidade ainda é considerado "o berço do conhecimento científico elaborado", apesar de hoje se apresentar de forma subserviente em relação ao 
capitalismo. A propósito, as palavras de Marilena Chauí, proferidas há um quarto de século continuam atuais:

Se a universidade brasileira está em crise, é simplesmente porque a reforma do ensino inverteu seu sentido e finalidade - em lugar de criar elites dirigentes, está destinada a adestrar mão-de-obra dócil para um mercado sempre incerto. E ela própria não se sente bem treinada para isto, donde sua “crise" (CHAUI, 1980, p. 34).

Paralelamente à este pensamento, neste estudo, buscou investigar como essas IES se estruturavam e funcionavam na prática e encontramos muitas outras variações. Configurações com estrutura simples naquela organização cujo poder está centralizado no líder, geralmente naquelas organizações pequenas ou iniciantes, ou numa burocracia carismática, onde há uma liderança muito forte. Um exemplo, na UCS, onde o reitor está no cargo à 17 anos, podemos identificar como um modelo de poder visualizado. Diferentes tipos de burocracia profissional, uma burocracia missionária, cujo poder está disperso e compartilhado e há um interesse muito fixo como a UNISINOS, identificado ao dados da PUCRS, onde há uma burocracia política, centralizada para os grupos de interesse que estão muito presentes, como o cargo ocupado à 12 anos, que ainda pode ser ainda caracterizado por uma burocracia mecanizada, clássica (BALDRIDGE, 1971; MEYER JUNIOR, 1998;).

A democracia, identificada nas formas mais correntes, mais atuais da UPF, URI e UNISC, por exemplo, onde há um certo poder do topo, mas um maior interesse pela inovação, os cargos são ocupados por menos tempo. E a forma divisional, que é muito descentralizada das ciências, geralmente das universidades que ainda não se constituíram fundamentalmente e nas quais as unidades têm um poder muito específico, muito descentralizado, como é o caso das seguintes IES comunitárias: UNIVATES, UNICRUZ e UNIFRA.

Em relação à formação desses gestores, percebe-se que as áreas das Ciências Humanas e Direito (Socias Aplicadas), são maioria, o que paira a esta discussão, a falta de profissionais da área - administradores - que em sua grande maioria entendem que as atividades que envolvem gestão deveriam ser desenvolvidas por eles (DESIDERIO, 2004). E consequentemente, as estratégias para a tomada de decisão não estejam adequadas pela falta de conhecimento mais profundo que envolvem a gestão universitária.

Os gestores com essas áreas de formação, podem tomar por adotar estratégias guardachuvas, que é um tipo particular e interessante, que normalmente não se considera, em que metas são amplamente definidas pela liderança, mas que permitem aos autores a decisão sobre 
como melhor alcança-las. Assim, o objetivo maior dessa estratégia é deliberado, mas o caminhar em direção ao objetivo emerge da dinâmica das ações dos vários participantes (HARDY; FACHIN, 2000). E ainda estratégias desconexas, que ocorrem em partes distintas da organização e não têm nenhuma relação ou mesmo contradizem as estratégias ditas organizacionais, que podem ser deliberadas ou emergentes. Ou seja, a universidade tem várias estratégias, dependendo do grupo, dependendo da vinculação do grupo com outros grupos, um grupo de administração, um outro grupo de física, são estratégias aparentemente desconexas, mas fundamentalmente ligadas ao modelo de universidade do Comung.

Em relação as estratégias formatadas pelo Comung, as IES comunitárias buscam estratégias consensuais, negociadas entre os membros, pois como demostra os dados do Quadro 1, o número de alunos, é um indicador para fatores de sempenho das IES, e que precisam ser administrados no contexto da economia, política atuais (COMUNG, 20016).

As IES localizadas na região metropolitana, possuem maior capacidades de prospectar alunos, com estratégias impostas, que referem-se à imposição de diretrizes de fora da organização para ela mesma, e que ao verificar-se as estratégias impostas, que vêm doprópria mercada, das IES concorrentes próximas ou na mesma cidade, por exemplo a PUCRS e o Centro Universitário Metodista.

Essas estratégias de gestão em universidades, são conceitos são fundamentais, e que em relação ao conceito de gestão que foi adotado nesta discussão é o de que, gestão é tomar decisões, e tomar decisões implica conhecer a organização em que se está e com elas conviver (MEYER; BANGOLIM, 2006).

As IESs membros do Comung são formatadas para atuarem de acordo com o modelo de administração participativa, com diferentes órgãos colegiados para orientar o processo decisório, os quais também contribuiem para limiar a atuaçao autoritária de um reitor. Conformando a ação dos reitores também estão os aspectos culturais e a origem de cada IESs tendo em vista que nem todas são efetivamente da comundidade, como se observa na história das univerisdades não são formadas a partir de uma congregação religiosa. A PUC/RS, por exemplo, por ser de propriedade de uma congregacao religiosa , tem decisões determinadas por instâncias superiores e menos do corpo docente.

Aquelas IESs estruturadas para atuarem de acordo com o modelo de gestão administração participativa pouco conhecem do modelo e orientam as práticas seguindo o modelo clássico de gestão, em especial seguindo as determinacoes rígidas do modelo 
burocrático. A respeito, Laus (2011) afirma que a gestão universitária contemporânea propõe distanciamento dos tradicionais modelos burocráticos e orienta ações pautadas nos fundamentos da autogestão, na participação ativa das pessoas e nas dimensões da sustentabilidade.

\section{CONSIDERAÇÕES FINAIS}

As IESs comuntárias brasileiras membro do Comung se apresentam como universidades que tem um compromisso público e social julgado e avaliado pelos pares, copartícipes do processo decisório da gestão dos recursos. Ao mesmo tempo, a comunidade que a instituiu regula, julga e conformo as decisões, que obrigatoriamente precisam estar voltadas às dimensões econômica, social e ambiental da sustentabilidade organizacional. Por essa razão, o perfil do gestor tem implicacão direta com os resultados alcançado pela IES, tendo em vista que é preciso atender aos diferentes stakeholders e ao mesmo tempo compartilhar das ansiedades de ser docente e estar Reitor.

Os dados de performance organizacional evidenciam, de forma preliminar considerando que este é um estudo exploratório, que há correlacão do perfil de um dos gestores principais das IESs membros do Comung, o Reitor, com os resultados observados nos Balanços instituicionais e no reconhecimento externo de diferentes organizações certificadoras de indicadores de sustentabilidade, em especial pela concessão de prêmios pela responsabilidade social e outros.

Os resultados indicam ainda que a formação profissional do gestor das universidades comunitárias apresenta relação positiva com os resultados organizacionais e com o modelo de gestão adotado. Profissionais formandos na área de Ciências Sociais Aplicadas possuem melhor desempenho para a tomada de decisões, num plano inicial, parece ser necessário e conveniente uma discussão sobre o papel do gestor. Há quase um consenso de que a principal função do gestor é de natureza pedagógica; na prática, no entanto, o tempo disponível, numa carga horária insuficiente, acaba consumido quase que integralmente em atividades administrativas. Neste sentido, podem ser apontadas algumas alternativas para discussão no âmbito institucional. 


\section{REFERÊNCIAS}

BITTAR, M. Unijuí: expressão do segmento comunitário. In: MOROSINI, M. (Org.). A universidade no Brasil: concepções e modelos. Brasília: Instituto Nacional de Estudos e Pesquisas Educacionais Anísio Teixeira, 2006.

BRASIL. MEC. SEF. Referenciais para formação de professores. Brasília: MEC/Secretaria de Educação Fundamental, 1999.

CARDIM, G.; A. O que envolve a gestão universitária em tempos de mudança. Fac. Belas Artes de São Paulo, 2000.

CHIZZOTI, Antonio. Pesquisas em ciências humanas e sociais. São Paulo: Cortez, 1998.

CFA. Conselho Federal de Administração. Perfil, formação, atuação e oportunidades de trabalho do administrador: pesquisa nacional. 5.ed. Brasília: CFA, 2011.

CHAUI, M. O que é ideologia. São Paulo: Brasiliense, 1980.

COHEN, M.; MARCH, J.; OLSEN, J. P. Garbege can model of organization choice. Administrative Science Quaterly, v 17, n. 1, p. 1-25, 1972.

COMUNG. Disponível em <http:// www.comung.com.br> Acesso em: 05 ago. 2016.

DESIDERIO, M. Desafios da gestão universitária. Revista de Administração Pública, v. 40, n. 1, p. 46-55, 2004.

HARDY, C.; FACHIN R. Gestão estratégica na universidade brasileira: teoria e casos. Porto Alegre: UFRGS, 1996.

Gestão estratégica na universidade brasileira: teoria e casos. 2. Ed. Porto Alegre: UFRGS, 2000 .

FRANTZ, W. As funções sociais da universidade: o papel da extensão e a questão das comunitárias. Ijuí: Unijuí, 2002.

LONGHI, M. S. Universidade de Passo Fundo condições de pesquisa e projeções. In: FRANCO, M. E. D. P. (Org). Universidade, pesquisa e inovação: o Rio Grande do Sul em perpectiva. Porto Alegre: Edipucrs, 1998.

MEYER J. V. Teoria e prática de gestão universitária. Cadernos - Centro Universitário São Camilo, São Paulo, v. 4, n.1, p. 49-59, jan./jun. 1998.

MEYER J. V. Novo conceito e as habilidades do administrador universitário. In: MEYER JUNIOR, V. MURPHY, P. Dinossauros, gazelas e tigres: novas abordagens da administração universitária: um diálogo Brasil e EUA. Florianópolis: Insular, 2000. 
MEYER J. V.; MANGOLIM, L. Estratégias em universidades privadas: estudos de casos. In: ENCONTRO DA ANPAD, 30, 2006, Salvador. Anais do..., Salvador, BA, 2006. CD Rom

NEVES, R. Ciência e tecnologia no Brasil. In: SOARES, S. (Org). A educação superior no Brasil. Brasília: Coordenação de Aperfeiçoamento de Pessoal de Nível Superior, 2002. p. 205-250.

ROSSATO, R.Universidade: nove séculos de história. 2. ed. rev. e ampl. Passo Fundo: UPF, 2005.

TASHIZAWA, T.; ANDRADE, B.; O.; O. Gestão de instituições de ensino. 2. edição revista. Rio de Janeiro: FGV, 2001.

ZABALZA, M. Ensino universitário: seu cenário e seus protagonistas. Porto Alegre: Artmed, 2007. 